\title{
Spatial relationships among the cellular tapetum, visual streak and rod density in dogs
}

\author{
Yasuhiro YAMAUE ${ }^{1,2)}$, Yoshinao Z. HOSAKA ${ }^{1)}$ and Masato UEHARA ${ }^{1) *}$ \\ ${ }^{1)}$ Department of Veterinary Anatomy, Faculty of Agriculture, Tottori University, Tottori 680-8553, Japan \\ ${ }^{2)}$ Department of Basic Veterinary Science, The United Graduate School of Veterinary Science, Yamaguchi University, Yamaguchi 753-8515, \\ Japan
}

(Received 1 September 2014/Accepted 3 October 2014/Published online in J-STAGE 30 October 2014)

\begin{abstract}
The dog visual system is well suited to dim light conditions due to rod-dominated retina and the reflective tapetum. The topographical distributions of rods and thickness of the tapetum of the dog were quantified in retinal whole mounts stained with thionine, and spatial relationships among the tapetum, rod density and visual streak of high ganglion cell density were elucidated. The relationship between the retina and tapetum was analyzed in parasagittal sections stained with thionine or hematoxylin-eosin. The tapetum was thick in its center, and the thickest part consisted of 9 to 12 tapetal cell layers. Rod density ranged from 200,000 to 540,000/ $\mathrm{mm}^{2}$. Maximum rod density was found in the area dorsal to the visual streak, and the density in that area was significantly higher than the rod density in the visual streak and accorded spatially with the thickest part of the tapetum. The horizontal visual streak was found over the horizontal line through the optic disc in the temporal half and extended slightly into the nasal half. The central area of the highest density of ganglion cells was approximately located midway between the nasal and temporal ends of the visual streak. The visual streak was located within the tapetal area, but ventrally to the thick part of the tapetum.
\end{abstract}

KEY WORDS: eye, ganglion cell, rod, tapetum, visual streak

doi: 10.1292/jvms.14-0447; J. Vet. Med. Sci. 77(2): 175-179, 2015

According to Miller and Murphy [13], the canine visual system has adapted to exploit a particular ecological niche by enhancing performance under low light conditions, but still retaining good function under a wide array of lighting conditions, including daylight. Dogs employ several methods of improving vision for dim light, including utilization of rod-dominated retinas and the reflective tapetum. Carnivores are commonly known to have rod-dominated retinas. It has been shown that rods in the dog outnumber cones throughout the retina, even within the highest cone density region of the area centralis $[1,9,13,14]$. However, there have been few reports on the distribution of rod density in the dog.

The tapetum lucidum is an intraocular reflective tissue. The mammalian tapetum is a structural adaptation of the choroid and is interposed between the thin choriocapillary lamina beneath the retinal pigment layer and the proper substance of the choroid. It enhances scotopic vision by reflecting light that has passed through the retina to stimulate again photoreceptors. The tapetal layer is composed of regularly arranged collagen fibers (i.e., the fibrous tapetum) in the horse, cow, sheep, elephant, sirenians and cetaceans or of specific rectangular-shaped cells (tapetal cells) (i. e., the cellular tapetum) in carnivores $[15,17]$. Tapetal cells are tightly packed with bundles of membrane-bound rodlets as the reflecting material [12]. The cellular tapetum in the dog

*Correspondence to: Uehara, M., Department of Veterinary Anatomy, Faculty of Agriculture, Tottori University, Tottori 6808553, Japan. e-mail: muehara@muses.tottori-u.ac.jp

(C)2015 The Japanese Society of Veterinary Science

This is an open-access article distributed under the terms of the Creative Commons Attribution Non-Commercial No Derivatives (by-nc-nd) License $<$ http://creativecommons.org/licenses/by-nc-nd/3.0/>. is a rounded triangle in shape, with the base oriented horizontally and the apex located dorsally to the optic disc. The base usually has contact with the optic disc. The tapetum in the dog is commonly thickest in its center [12, 15, 23, 24]. The dog tapetum shows considerable individual variation in its extent and thickness [6, 10, 24].

It has been suggested that the tapetum enhances night vision, but scattered light from the tapetum reduces visual discrimination during daylight because the visual streak is located on the tapetum $[7,8,13,15]$.

In the dog, the visual streak of a high ganglion cell density is mostly located in the temporal retina extending to the nasal retina $[5,11,16]$. The visual streak is located in the tapetal area of the retina, suggesting that vision in dim light may be enhanced, but that resolution of an image in bright light may be reduced by scattered light from the tapetum [7, 8, 13, 15].

In vision research, a multitude of retinal elements has been studied separately. Also, anatomists have studied each retinal element separately. The dog is well suited for scotopic vision. Since the tapetum is very important in scotopic vision, we investigated the distribution of tapetum thickness in this study. We also investigated rod densities in selected areas related to the tapetum and visual streak. Finally, we examined spatial relationships among the visual streak, rod density and distribution of tapetum thickness in the dog.

\section{MATERIALS AND METHODS}

Eyes were obtained from adult untreated crossbred dogs that were euthanized by carbon dioxide for reasons unrelated to the present investigation. The eyes were removed and fixed within $1 \mathrm{hr}$ postmortem. The eyes used in this study each had a normal tapetum, being triangular with rounded 
corners and a smooth contour. Its base was in contact with the optic disc.

All experiments were conducted in accordance with the guidelines of the Animal Care and Use Committee of Tottori University.

Whole mounts: In order to determine the relationship between rod density and ganglion cell density, 3 eyes from 3 animals were used for whole mounts (DR11-13). The enucleated eyes were opened by an encircling cut, and the posterior eyecups were fixed by immersion in $10 \%$ formalin. Each retina was dissected free from the eye within $2 \mathrm{hr}$ after the start of fixation and laid on a gelatinized coverslip. Horizontal and vertical cuts were made to flatten out the retina. The retina was fixed to the coverslip by exposure to formalin vapor for several hr and then stained with thionine for Nissl staining, dehydrated in a series of graded alcohols, cleared in xylene and coverslipped using Canada balsam. Wholemounted specimens were pasted to a 1-mm grid transparent film to determine the photographic points for retinal ganglion cells and rods. We took micrographs of ganglion cells at $10 \times$ or $20 \times$ and rods at $40 \times$ or $100 \times$ were all taken at the center of the 1-mm grid along the meridian lines through the visual streak and optic disc. In addition, micrographs of area with maximum density of ganglion cells and its dorsal and ventral adjacent areas, regardless of the grid, were also taken.

Histological sections: In order to determine the relationship between ganglion cell density and thickness of the tapetum, both eyes from each of 5 animals were enucleated. After one fresh eye was confirmed to have, the eyes were injected with $3 \%$ glutaraldehyde in $10 \%$ formalin into the vitreous body. After fixation, the posterior cup of each eye was dehydrated, embedded in nitrocellulose (Colloidin, Wako, Osaka, Japan), cut at 30-40 $\mu \mathrm{m}$ in the meridian direction and then stained with hematoxylin-eosin or thionine. In order to obtain distribution maps of the tapetum thickness, additional 3 eyes from 3 animals were used. After fixation by the above-described method, the posterior cup of each eye was embedded in paraffin, cut at $5 \mu \mathrm{m}$ every $500 \mu \mathrm{m}$ in the meridian direction and stained with hematoxylin-eosin. Distribution maps of tapetum thickness were reconstructed from the sections.

Statistical analysis: Images of rods and ganglion cells in selected areas of the whole-mounted retina were obtained using an Olympus BH-2 microscope with an Olympus DXC-5500/OL camera and DP controller software (Olympus, Tokyo, Japan) with $40 \times$ or $100 \times$ objectives. Significant differences in rod density among the retinal areas were tested using one-way analysis of variance (ANOVA), and post hoc multiple comparisons were performed using Tukey-Kramer multiple comparison tests. A $P$-value of 0.05 was defined as significant.

\section{RESULTS}

Topography of Tapetal Thickness: In this study, we counted the number of layers as the thickness of a normal tapetum, which was rounded triangular in shape with the smooth contour. Its base had contact with the optic disc. The tapetum was thick in the central part (Fig. 1). The thickest part of tapetum deviated temporal from the center consisting of 9 to 12 tapetal cell layers (Fig. 2).

Rod Densities: In the histological observations without statistical examination, there was a clear difference in rod densities of the selected areas (Fig. 3). Rod density was higher in the dorsal areas to the optic disc and to the visual streak and lower in the peripheral retina.

In the two normal retinas, multiple areas were selected as areas for examination of rod densities as shown in Figs. 4A and 5A. Rod densities in the selected areas showed a significant difference in the two normal retinas based on the results of one-way ANOVA. In DR11 (Fig. 4B), rod density ranged from $215,000 / \mathrm{mm}^{2}$ to $532,000 / \mathrm{mm}^{2}$ and was $384,000 / \mathrm{mm}^{2}$ on average. In DR12 (Fig. 5B), rod density ranged from 195,000 to $538,000 / \mathrm{mm}^{2}$ and was $365,000 / \mathrm{mm}^{2}$ on average. The maximum densities were 2.5 to 2.7 times greater than the minimum densities in DR11 and DR12, respectively. Overall, rod density did not differ greatly throughout the selected areas. Along the meridian line through the visual streak, maximum rod density was found in the dorsal area to the visual streak and was significantly higher than the densities in the visual streak (Figs. 4B and 5B). Along the meridian line through the optic disc, rod density ranged from $416,000 / \mathrm{mm}^{2}$ to $199,000 / \mathrm{mm}^{2}$ and was $318,000 / \mathrm{mm}^{2}$ on average. Maximum rod density, corresponding approximately to the thick area of the tapetum, was found in the dorsal area to the optic disc (Fig. 5C), but markedly lower than the densities in the areas 4 and 5. However, except for area 14, rod densities made a little difference with each other, and the maximum density (area 18) was only 1.5 times greater than the density in area 13.

Visual Streak and Tapetum: The horizontal visual streak was found over the horizontal line through the optic disc in the temporal half and extended slightly into the nasal half (Figs. 4A, 5A and 6). The central area of the highest density of ganglion cells was approximately located intermediate between the nasal and temporal ends of the visual streak. In histological sections of the retina and choroid, the visual streak was located within the tapetal region, but ventrally to the thick area of the tapetum (Fig. 2B and 2C).

\section{DISCUSSION}

Relationship between the tapetum and the visual streak: It has been thought that the tapetum is well suited for night vision, but may impair visual resolution in daylight vision by scattered light $[7,8,13,15]$. In this study, the visual streak in dogs was found to be located within the tapetal area, but not on the thickest part of the tapetum. Although the positional relationship between the tapetum and the visual streak would somewhat relieve the negative effect of the tapetum during daylight, there is concern about the possibility of the tapetum impairing visual resolution in daylight vision. A similar relationship has been reported for the horse eye [20]. They suggest that the tapetum would not have a serious influence on visual acuity in daylight vision. There may be three reasons. First, the wavelength of the reflected light from the tapetum 


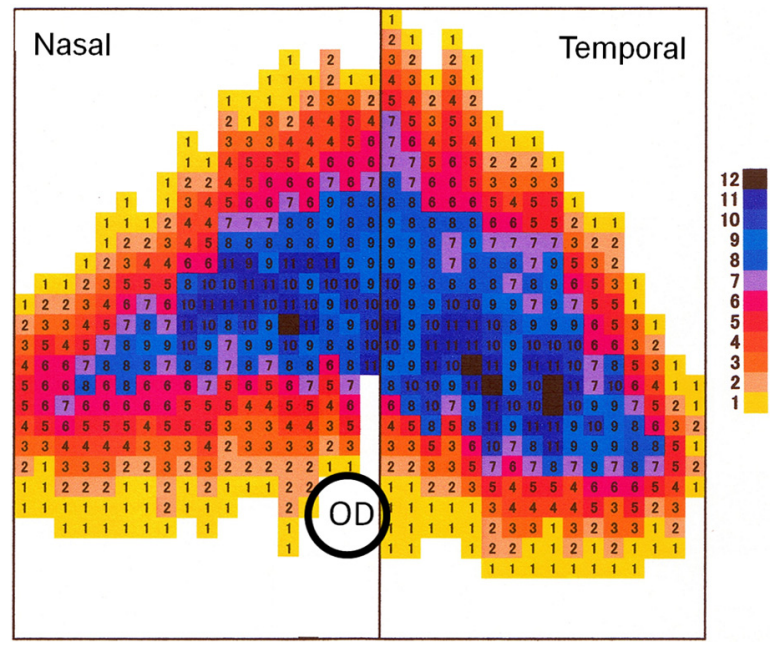

Fig. 1. Distribution of tapetal thickness. The tapetum is thick in the central region. The numbers indicate the layer number of tapetal cells. OD, optic disc. is far from the spectral peak of photopigment sensitivity of $\mathrm{M} / \mathrm{L}$ cones. Second, the anatomically estimated visual acuity, which is estimated from the eye size and ganglion cell density, accords well with behavioral visual acuity, which is estimated from observations of vision-dependent behavior. Finally, the visual streak is located in the thin tapetal area. Furthermore, for most species including dog and horse, behavioral visual acuity is very close to anatomically estimated acuity [4, 22]. Therefore, the tapetum in dogs would not reduce significantly visual acuity in daylight vision.

Relationship between the tapetum and rod density: There have been a few studies on rod density in dogs [14]. According to Mowat et al. [14], rod density is $501,000 / \mathrm{mm}^{2}$ in the area centralis of the visual streak and $304,800 /$ $\mathrm{mm}^{2}$ in the inferior periphery. The area centralis contains a higher density of both rods and cones. In this study, rod density was highest in the dorsal retina to the area centralis. However, Mowat et al. [14] measure rod density only in two areas, the area centralis and the inferior periphery. The spotted hyena has a cellular tapetum in the eye. Rod
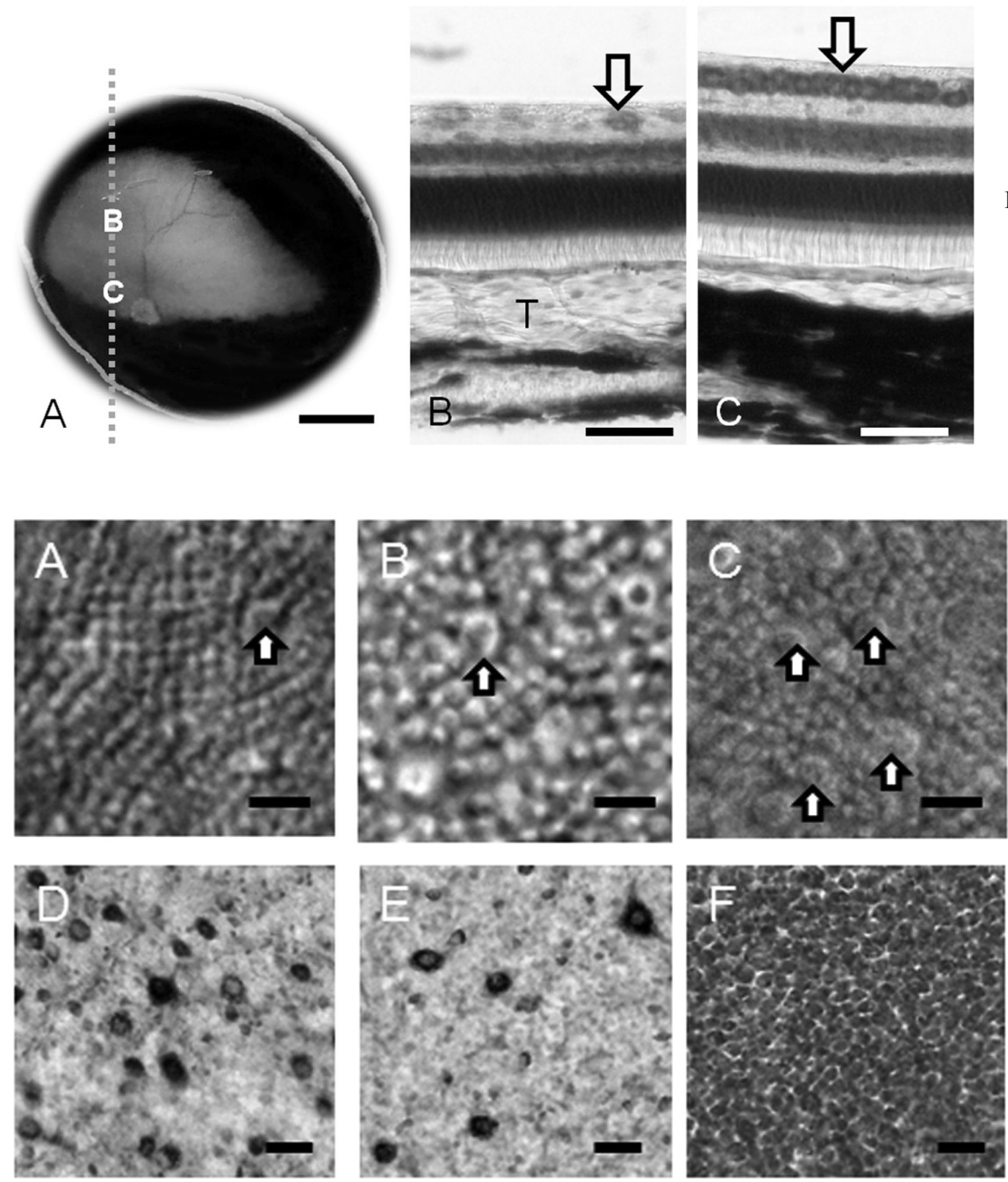

Fig. 2. Macroscopic photograph of the ocular fundus with a normal tapetum in the right eye (A). Micrographs $(\mathrm{B}, \mathrm{C})$ taken from the parasagittal section which is cut along the dashed line. $\mathrm{B}$, the thickest part of the tapetum; $\mathrm{C}$, the area centralis in the visual streak. Thionine stain (B, C). T, Tapetum; Arrow, ganglion cells. Scale bar $=5$ $\mathrm{mm}$ in $\mathrm{A}$ and $50 \mu \mathrm{m}$ in $\mathrm{B}$ and $\mathrm{C}$.
Fig. 3. Rods $(\mathrm{A}-\mathrm{C})$ and ganglion cells (D-F) in retinal areas 4 (A, D), 2 (B, E) and $9(\mathrm{C}, \mathrm{F})$ of DR12 (Refer to caption of Fig. 5). D-F are taken from the same microscopic fields of A-C, respectively. In area 4 corresponding to the thickest part of the tapetum, rods are small in diameter, and ganglion cells are intermediate in density. In area 2 corresponding to the dorsal thin part of the tapetum, rods are large in diameter, and ganglion cells are low in density. In area 9 corresponding to the visual streak, rods are intermediate of areas 2 and 4 in diameter, and ganglion cells consist exclusively of a small type showing highest density. Arrows, cones. Scale bar $=10 \mu \mathrm{m}(\mathrm{A}-\mathrm{C})$ and $100 \mu \mathrm{m}$ (D-F). 
A

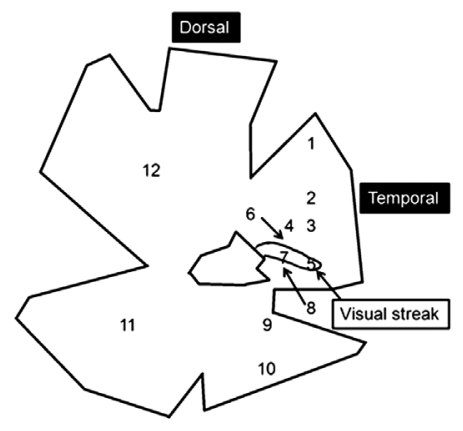

B

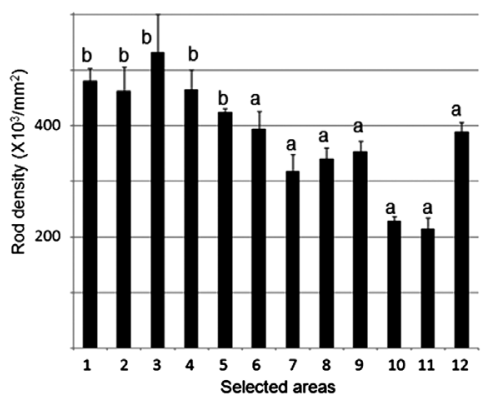

Fig. 4. A, Illustration of a whole-mounted retina showing the visual streak and selected areas for rod density in DR11. B, Rod densities along the meridian line through the visual streak and of some other areas (areas 1,11 and 12) as reference. The density in area 3 , which has the maximum density of rods, is significantly higher than the densities in a (areas 6-12), and the density in area 7 in the central area is significantly lower than the densities b (areas 1-5). With significant difference between different marks $P<0.05$.

A

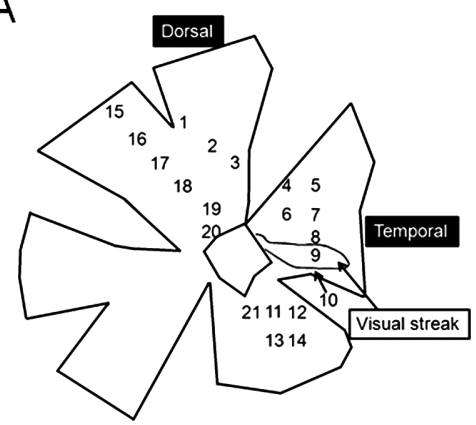

B

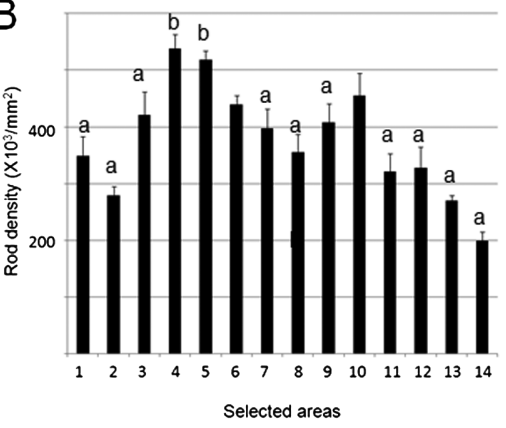

C

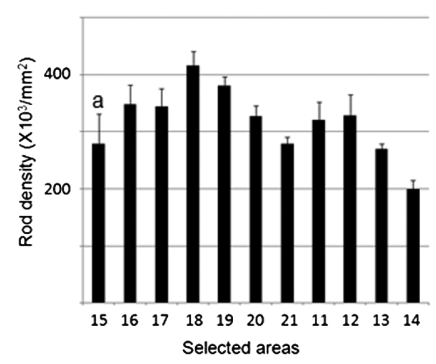

Fig. 5. A, Illustration of a whole-mounted retina showing the visual streak and selected areas for rod density in DR12. B, Rod densities along the meridian line through the visual streak. The density in area 4 , which has the maximum density of rods, is significantly higher than the densities in a (areas 1-3, 7-9 and 11-14) among areas 1-14, and the density in area 9, which is the central area of the highest density of ganglion cells, is significantly lower than the densities of $b$ (areas 4 and 5) among areas 11-14. With significant difference between different marks $P<0.05$. C, Rod densities along the meridian line through the optic disk. In these areas, the maximum density (area 18) is significantly higher than the densities in a (area15) in the dorsal retina $(P<0.05)$.

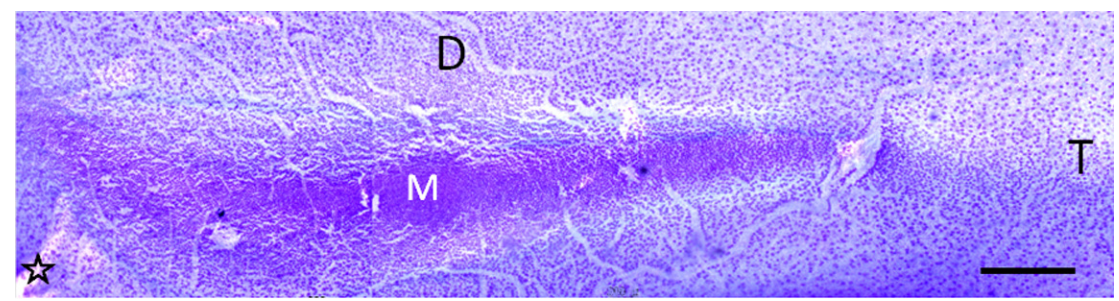

Fig. 6. Micrograph of the visual streak from a whole-mounted retina. M, central area with the maximum density of ganglion cells; D, dorsal; T, temporal; star, optic disc. Scale bar $=500 \mu \mathrm{m}$.

density in the hyena retina shows a linear fall-off along a central-peripheral gradient, ranging from $566,300 / \mathrm{mm}^{2}$ to $289,400 / \mathrm{mm}^{2}$ [2]. In the cat eye, rod density is lowest in the central area $\left(300,000-350,000 / \mathrm{mm}^{2}\right)$, increases toward the peripheral direction with maximum density of $550,000 / \mathrm{mm}^{2}$ upon reaching the periphery and then decreases peripherally near the ora serrata $\left(300,000 / \mathrm{mm}^{2}\right)$. Rod density changes in a similar fashion in both the dorsoventral and nasotemporal axes [21]. Therefore, there is no relation between rod density and the thickness of the tapetum in the cat and hyena. In the present study, rod density ranged from $199,000 / \mathrm{mm}^{2}$ to $538,000 / \mathrm{mm}^{2}$ being similar to that in dogs [14], cats [21] and hyenas [2]. The maximum density area corresponded approximately to the thickest part of the tapetum. Why does 
not the maximum rod density area in the cat and hyena retinas correlate directly with the thickest area of the tapetum? The relationship between rod density and the thickness of the tapetum may be unclear, because rod density is not much different through the retina. Maximum rod density is less than twice to minimum rod density in the cat [21] and hyena [2]. Furthermore, the relationship between rod density and the thickness of the tapetum has not been focused in these studies.

There have been reports on rod density in ungulates [3, 18]. In sheep, a high-density area of rods forms a horizontally broad band located dorsally to the optic disc. The horizontal visual streak is located within the horizontal broad band of high rod density. Maximum rod density areas are dorsally located to the horizontal visual streak as well as the present study. The fibrous tapetum consists of the horizontal band and its dorsotemporal extension located dorsally to the optic disc. The horizontal visual streak locating dorsally to the optic disc has a dorsotemporal extension of a relatively high ganglion cell density. The horizontal visual streak with the dorsotemporal extension is located in the tapetal area. The thickest part of the tapetum is located dorsally to the horizontal visual streak $[18,19]$. Thus, spatial relationships of the tapetum, visual streak and rod density in the sheep are very similar to the present study. In the pig eye without the tapetum, the horizontal visual streak is dorsally located to the optic disc [8], and rod density is higher in the ventral half than in the dorsal half [3]. Results for pig and sheep eyes suggest that rod density does not have a close relationship with the visual streak. The visual streak is useful for daylight vision and provides high visual acuity, because of its high cone density. This may be another reason why a high density area of rods does not correspond to the visual streak.

\section{REFERENCES}

1. Ahnelt, P. K. and Kolb, H. 2000. The mammalian photoreceptor mosaic-adaptive design. Prog. Retin. Eye Res. 19: 711-777. [Medline] [CrossRef]

2. Calderone, J. B., Reese, B. E. and Jacobs, G. H. 2003. Topography of photoreceptors and retinal ganglion cells in the spotted hyena (Crocuta crocuta). Brain Behav. Evol. 62: 182-192. [Medline] [CrossRef]

3. Chandler, M. J., Smith, P. J., Samuelson, D. A. and MacKay, E. O. 1999. Photoreceptor density of the domestic pig retina. Vet. Ophthalmol. 2: 179-184. [Medline] [CrossRef]

4. Gianfranceschi, L., Fiorentini, A. and Maffei, L. 1999. Behavioural visual acuity of wild type and $b c l 2$ transgenic mouse. Vision Res. 39: 569-574. [Medline] [CrossRef]

5. Gonzalez-Soriano, J., Rodriguez-Veiga, E., Martinez-Sainz, P., Mayayo-Vicente, S. and Marin-Garcia, P. 1995. A quantitative study of ganglion cells in the German shepherd dog retina. Anat. Histol. Embryol. 24: 61-65. [Medline] [CrossRef]

6. Granar, M. I. K. S., Nilsson, B. R. and Hamberg-Nyström, H.
L. 2011. Normal color variations of the canine ocular fundus, a retrospective study in Swedish dogs. Acta Vet. Scand. 53: 13. [Medline] [CrossRef]

7. Hall, C. 2007. The impact of visual perception on equine learning. Behav. Processes 76: 29-33, discussion 57-60. [Medline] [CrossRef]

8. Hebel, R. 1976. Distribution of retinal ganglion cells in five mammalian species (pig, sheep, ox, horse, dog). Anat. Embryol. (Berl.) 150: 45-51. [Medline]

9. Jacobs, G. H., Deegan, J. F. 2nd., Crognale, M. A. and Fenwick, J. A. 1993. Photopigments of dogs and foxes and their implications for canid vision. Vis. Neurosci. 10: 173-180. [Medline] [CrossRef]

10. Janssens, G. H. R. R. 2011. Normal variation of the ocular fundus in dogs. Acta Vet. Scand. 53: 193-198.

11. Krinke, A., Schnider, K., Lundbeck, E. and Krinke, G. 1981. Ganglionic cell distribution in the central area of the beagle dog retina. Anat. Histol. Embryol. 10: 26-35. [Medline] [CrossRef]

12. Lesiuk, T. P. and Braekevelt, C. R. 1983. Fine structure of the canine tapetum lucidum. J. Anat. 136: 157-164. [Medline]

13. Miller, P. E. and Murphy, C. J. 1995. Vision in dogs. J. Am. Vet. Med. Assoc. 207: 1623-1634. [Medline]

14. Mowat, F. M., Petersen-Jones, S. M., Williamson, H., Williams, D. L., Luthert, P. J., Ali, R. R. and Bainbridge, J. W. 2008. Topographical characterization of cone photoreceptors and the area centralis of the canine retina. Mol. Vis. 14: 2518-2527. [Medline]

15. Ollivier, F. J., Samuelson, D. A., Brooks, D. E., Lewis, P. A., Kallberg, M. E. and Komáromy, A. M. 2004. Comparative morphology of the tapetum lucidum (among selected species). Vet. Ophthalmol. 7: 11-22. [Medline] [CrossRef]

16. Peichl, L. 1992. Topography of ganglion cells in the dog and wolf retina. J. Comp. Neurol. 324: 603-620. [Medline] [CrossRef]

17. Samuelson, D. A. 2007. Ophthalmic anatomy. pp. 37-148. In: Veterinary Ophthalmology (Gelatt, K. N. ed.), 4th ed., Blackwell, Ames.

18. Shinozaki, A., Hosaka, Y., Imagawa, T. and Uehara, M. 2010. Topography of ganglion cells and photoreceptors in the sheep retina. J. Comp. Neurol. 518: 2305-2315. [Medline] [CrossRef]

19. Shinozaki, A., Hosaka, Y., Imagawa, T. and Uehara, M. 2010. Relationship between distribution of tapetum fibrosum and retinal pigment epithelium in the sheep eye. J. Vet. Med. Sci. 72: 211-215. [Medline] [CrossRef]

20. Shinozaki, A., Takagi, S., Hosaka, Y. Z. and Uehara, M. 2013. The fibrous tapetum of the horse eye. J. Anat. 223: 509-518. [Medline]

21. Steinberg, R. H., Reid, M. and Lacy, P. L. 1973. The distribution of rods and cones in the retina of the cat (Felis domesticus). $J$. Comp. Neurol. 148: 229-248. [Medline] [CrossRef]

22. Timney, B. and Keil, K. 1992. Visual acuity in the horse. Vision Res. 32: 2289-2293. [Medline] [CrossRef]

23. Wen, G. Y., Sturman, J. A. and Shek, J. W. 1985. A comparative study of the tapetum, retina and skull of the ferret, dog and cat. Lab. Anim. Sci. 35: 200-210. [Medline]

24. Yamaue, Y., Hosaka, Y. Z. and Uehara, M. 2014. Macroscopic and histological variations in the cellular tapetum in dogs. J. Vet. Med. Sci. 76: 1099-1103. [Medline] [CrossRef] 